\title{
Electrochemical genosensors: definition and fields of application
}

\begin{abstract}
In biological fields such as medicine, detection of pathogenic bacteria and viruses and food safety and quality control, need to provide information in real time which motivates the search for alternative methods. Biosensors are the most attractive alternative providing simple, reliable, fast and selective detection systems compared with conventional methods like PCR, FISH, and ELISA which have some limitations. This review provides an overview of the definition of electrochemical genosensors and their fields of application showing their effectiveness as a quick and sensitive tool for detection of pathogenic bacteria, virus, GMOs and human diseases diagnosis.
\end{abstract}

Keywords: electrochemical genosensor, pathogenic bacteria, nanoparticles, DNA, probe
Volume 3 Issue 5 - 2017

\author{
Younes El Goumi \\ Laboratory of Agrifood and Health, Hassan I ${ }^{\text {st }}$ University, \\ Morocco
}
Correspondence: Younes El Goumi, Laboratory of Agrifood and Health, Faculty of Sciences and Techniques, Hassan Ist University, Settat, 2600, Morocco,
Email elgoumiyounes@hotmail.com

Received: November 21, 2017 | Published: December 08, 2017
Abbreviations: AuNPs, gold nanoparticles; ELISA, enzymelinked immunosorbent assay; FISH, fluorescence in situ hybridization; GMO, genetically modified organisms; LOD, limit of detection; PCR, polymerase chain reaction; ssG-DNA, single-stranded genomic DNA, $\mathrm{ZnO} / \mathrm{Pt}-\mathrm{Pb}$, zinc oxide/platinum-palladium

\section{Introduction}

The conventional methods used for specific sequences detection in nucleic acids based on DNA sequence polymerization (PCR) or DNA hybridization (FISH), present certain drawbacks such as the requirement of expensive equipment, time-consuming, laborious and in some case a low sensitivity. Therefore, biosensors are the most attractive alternative providing simple, reliable, fast and selective detection systems. An electrochemical biosensor is an analytical tool composed of bioreceptor that specifically recognizes a biological agent of interest (analyte), which results in a (bio) chemical signal converted by the transducer into an exploitable signal. ${ }^{1}$ Development and use of electrochemical genosensors are evolving at a rapid pace, the definition of the electrochemical genosensors and their classification can not unequivocally answer all details and nuances. Biosensors classification may be made according to the biological specificity conferring mechanism or to the mode of signal transduction or, alternatively, a combination of the two, ${ }^{1}$ for detailed definition and classification, I invite you to read the paper of Thévenot et al. ${ }^{1}$ \& Ozsos's book. ${ }^{2}$ In electrochemical genosensors, the bioreceptor can be a probe (small sequence of oligonucleotides, in case of electrochemical DNA-based genosensor) or an aptamer (synthetic oligonucleotides sequence, in case of electrochemical Aptamer-based genosensor) immobilized at the transducer surface, due to their affinity, these oligonucleotides sequences recognize the analyte (Nucleic acids) by complementarity making duplexes. The electrochemical DNA-based genosensors can be coupled with nanoparticles or nanocomposites to improve both oligonucleotides sequence immobilization on the transducer surface and sensitivity to hybridization..$^{3-7}$ The electrochemical techniques applied in genosensor can be used in different goals, e.g Differential Pulse Voltammetry (DPV) as analystical technique is usually used to measure the concentration of some specific electroactive species with high sensitivity. ${ }^{8}$ This paper is devoted to giving a general idea about the fields of application of electrochemistry, such as medicine, plant breeding, food safety and quality control, and bacterial and viral analysis.

\section{Plants breeding, food safety and quality control}

In the case of viruses that affect fruit trees, Plum Pox virus (Sharka) is one of the most devastating viral diseases of stone fruits worldwide, with a significant impact on agronomy and economics. ${ }^{9}$ As reported by, ${ }^{9}$ the use of electrochemical genosensor provides a rapid and effective alternative for Plum Pox detection, in their study the genosensor was based the ion-channel mechanism. The concerns raised by allergic consumers exposed to foods containing allergens, this is one of the causes that have increased the importance of food safety. In addition, the introduction of GMOs into the food and feed market has given rise to growing concern over their controversial safety for human consumption and biodiversity loss. ${ }^{10}$ Electrochemical genosensors remain an effective and promising tool for the detection of GMOs. Indeed, Moura-Melo et al. ${ }^{11}$ were able to determine transgenic maize and soybean, using an electrochemical genosensor based on DNA sequence characteristic of the $35 \mathrm{~S}$ promoter derived from the cauliflower mosaic virus (CaMV). In addition, a rapid GMO detection in maize ( $\mathrm{CBH} 351$ variety) was done through an electrochemical genosensor based on loop-mediated isothermal amplification. ${ }^{12}$ This last technique provides a rapid and sensitive method of detection of the presence of meat species in raw or processed foods. ${ }^{13}$ In the case of foodborne pathogens such as Listeria monocytogenes electrochemical genosensor based on loop-mediated isothermal amplification can provide an effective tool for its detection in A very low limit of detection and with high confidence. ${ }^{14}$ In Vibrio cholera and Escherichia coli O157:H7, Low et al. ${ }^{15}$ \& Abdalhai et al. ${ }^{16}$ reported the efficiency of detecting the presence of these pathogenic bacteria even with low LOD (limit of detection) based on the use of electrochemical genosensors.

\section{Medicine, bacterial and viral analysis}

Conventionally, the detection and identification of bacteria mainly rely on specific microbiological and biochemical identification methods, which require at least 3 and as many as 7 days to yield 
results. ${ }^{17}$ Electrochemical genosensors offer a quick tool for detection and diagnosis, based on the use of specific probe for gene of virulence, such inlA and hly gene for Listeria monocytogenes , ${ }^{7,17}$ or oligonucleotides isolated from conserved region of the bacteria genome for Streptococcus pneumonia. ${ }^{18}$ Infection by Streptococcus pyogenes causing damage of heart valves in human, as reported by ${ }^{8}$ an electrochemical genosensor based on sepB gene probe can offer a rapid detection in few minutes $(30 \mathrm{~min})$ of the infection with a lower LOD of $0.10 \mathrm{ng}$ of ssG-DNA per $6 \mu$ l (human throat swab sample s). Based on oligonucleotides probe that was identified from the 16s rRNA coding region of the Escherichia coli O157:H7 genome, Pandey et al. ${ }^{19}$ have coupled it with cystine flower-gold particles matrice to improve its immobilization, their genosensor exhibited a linear response with LOD of $1 \times 10^{-15} \mathrm{M}$ provide a selective tool for Escherichia coli O157:H7. For the same strain of E. coli, the uses of nanocomposites can improve the detection and decrease the LOD form $10-6$ to $10^{-16} \mathrm{M}^{5}$

The efficiency of use of electrochemical genosensors was shown in several virus detections such as $\mathrm{HIV},{ }^{20}$ papllivirus, ${ }^{21}$ dengue virus ${ }^{4}$ and hepatitis virus. ${ }^{22-23}$ Dengue fever has become a global health concern, as it is the most prevailing vector-borne disease causing predominant mortality and morbidity. Conventional diagnostic assays employed for dengue detection such as isolation of the virus, detection of DENV specific antibodies, ELISA, and PCR have some limitations. ${ }^{4}$ They reported that the coupling of smart nanomaterials as $\mathrm{ZnO} / \mathrm{Pt}-\mathrm{Pb}$ nanocomposite in electrochemical genosensors improve the immobilization and sensitivity to virus DNA target, with LOD of $4.3 \times 10^{-5} \mathrm{M}$. In Hepatitis virus which is a global health problem, Honorato Castro et al. ${ }^{23}$ established for the first time an electrochemical genosensor incorporating a specific oligonucleotides probe detecting Hepatitis B virus, by direct (detect hybridization by direct oxidation of guanosine and adenosine base) or indirect (using ethidium bromide as a hybridization indicator) electrochemical transduction, based on a graphite electrode modified with a poly(4aminophenol) matrix. This efficiency of the use of nanocomplexes has also been reported by Rolim et al. ${ }^{24}$ whose used electrochemical sandwich-type genosensors based upon DNA-AuNPs for detection of a Systemic Arterial Hypertension (SAH) polymorphism located in intron 16 of the Angiotensin-converter enzyme (ACE) gene (related to heart diseases, especially blood hypertension, its early detection is of great biomedical interest). The use of biosensors has proved their effectiveness in the diagnosis of cancer. Indeed, Xu et al..$^{25}$ established an electrochemical impedance spectroscopic DNA for the detection of human mammaglobin (MG) in breast cancer patients. Compared to PCR, their biosensor has proved its effectiveness, its sensibility of detection with LOD $5 \times 10^{-5} \mathrm{M}$, and time-saving.

\section{Conclusion}

The coverage of biosensor use will never be limited in view of the rapid evolution of these tools. An effort was made to improve their detection efficiency and sensitivity, we have seen the integration of nanoparticles, nanocomplexes, nanostructures extending their application which make progress in the electrochemical genosensors for detection of pathogenic bacteria, virus, plants breeding, food safety and control quality...etc. expending their fields of application. Even if with the challenge to develop a practically applicable and portable device in some cases, electrochemical genosensors still the most attractive alternative providing simple, reliable, fast and selective detection systems.

\section{Acknowledgements}

None.

\section{Conflict of interest}

The author declares no conflict of interest.

\section{References}

1. Thévenot DR, Toth K, Durst RA, et al. Electrochemical biosensors: recommended definitions and classification. Biosensors Bioelectron. 2001;16(1-2):121-131.

2. Ozsoz MS. Electrochemical DNA Biosensors. 1st ed. USA: CRC Press: 2012. $400 \mathrm{p}$.

3. Mohammed AM, Ibraheem IJ, Obaid AS, et al. Nanostructured ZnObased biosensor: DNA immobilization and hybridization. Sensing and Bio-Sensing Research. 2017;15:46-52.

4. Singhal C, Pundir CS, Narang J. A genosensor for detection of consensus DNA sequence of Dengue virus using $\mathrm{ZnO} / \mathrm{Pt}-\mathrm{Pd}$ nanocomposites. Biosensors Bioelectron. 2017;97:75-82.

5. Tiwari I, Singh M, Pandey CM, et al. Electrochemical detection of a pathogenic Escherichia coli specific DNA sequence based on a graphene oxide-chitosan composite decorated with nickel ferrite nanoparticles. RSC Advances. 2015;5(82):67115-67124.

6. Zhang Y, Zhang K, Ma H. Electrochemical DNA biosensors based on gold nanoparticles/Cysteamine/Poly(glutamic acid) modified electrode. Am J Biomed Sci. 2009;(1):115-125.

7. Niu X, Zheng W, Yin C, et al. Electrochemical DNA biosensor based on gold nanoparticles and partially reduced graphene oxide modified electrode for the detection of Listeria monocytogenes HLY gene sequence. Journal of Electroanalytical Chemistry. 2017;806:116-122.

8. Kaushal A, Singh S, Kala D, et al. SpeB genosensor for rapid detection of streptococcus pyogenes causing damage of heart valves in human. Cell Mol Biol. 2016;(62):140.

9. Malecka K, Michalczuk L, Radecka H, et al. Ion-channel genosensor for the detection of specific DNA sequences derived from plum pox virus in plant extracts. Sensors (Basel). 2014;14(10):18611.

10. Martín-Fernández B, Manzanares-Palenzuela CL, López MSP, et al. Electrochemical genosensors in food safety assessment. Critical Reviews in Food Science and Nutrition. 2017;57(13):2758-2774.

11. Moura-Melo S, Miranda-Castro R, De-Los-Santos-Álvarez N, et al. A quantitative pcr-electrochemical genosensor test for the screening of biotech crops. Sensors (Basel). 2017;17(4):881.

12. Ahmed MU, Saito M, Hossain MM, et al. Electrochemical genosensor for the rapid detection of GMO using loop-mediated isothermal amplification. Analyst. 2009;134(5):966-972.

13. Ahmed MU, Hasan Q, Mosharraf Hossain M, et al. Meat species identification based on the loop mediated isothermal amplification and electrochemical DNA sensor. Food Control. 2010;21(5):599-605.

14. Garrido-Maestu A, Azinheiro S, Carvalho J, et al. Development and evaluation of loop-mediated isothermal amplification, and Recombinase Polymerase Amplification methodologies, for the detection of Listeria monocytogenes in ready-to-eat food samples. Food Control. 2018;(86):27-34.

15. Low KF, Chuenrangsikul K, Rijiravanich P, et al. Electrochemical genosensor for specific detection of the food-borne pathogen, Vibrio cholerae. World J Microbiol Biotechnol. 2012;28(4):1699-1706. 
16. Abdalhai MH, Fernandes AM, Xia X, et al. Electrochemical genosenso to detect pathogenic bacteria (Escherichia coli $\mathrm{O} 157: \mathrm{H} 7$ ) as applied in real food samples (Fresh Beef) To improve food safety and quality control. J Agric Food Chem. 2015;63(20):5017-5025.

17. Bifulco L, Ingianni A, Pompei R. An internalin a probe-based genosensor for Listeria monocytogenes detection and differentiation. BioMed Research International. 2013. 6 p.

18. Ferreira FP, Honorato-Castro AC, Da Silva JV, et al. A novel polymerbased genosensor for the detection and quantification of Streptococcus pneumoniae in genomic DNA sample. Polymer Engineering \& Science. 2017.

19. Pandey CM, Tiwari I, Sumana G. Hierarchical cystine flower based electrochemical genosensor for detection of Escherichia coli O157:H7. RSC Advances. 2014;4(18):31047-31055.

20. Zhang D, Peng Y, Qi $H$, et al. Label-free electrochemical DNA biosensor array for simultaneous detection of the HIV-1 and HIV-2 oligonucleotides incorporating different hairpin-DNA probes and redox indicator. Biosensors Bioelectron. 2010;25(5):1088-1094.
21. Dell Atti D, Zavaglia M, Tombelli S, et al. Development of combined DNA-based piezoelectric biosensors for the simultaneous detection and genotyping of high risk human papilloma virus strains. Clinica Chimica Acta. 2007;383(1-2):140-146.

22. Skládal P, Dos Santos Riccardi C, Yamanaka H, et al. Piezoelectric biosensors for real-time monitoring of hybridization and detection of hepatitis C virus. J Virol Methods, 2004;117(2):145-151.

23. Honorato Castro AC, França EG, De Paula LF, et al. Preparation of genosensor for detection of specific DNA sequence of the hepatitis B virus. Applied Surface Science. 2014;314:273-279.

24. Rolim T, Cancino J, Zucolotto V. A nanostructured genosensor for the early diagnosis of systemic arterial hypertension. Biomed Microdevices. 2015;17(1):3.

25. Xu X, Weng X, Liu A, et al. Electrochemical genosensor for detection of human mammaglobin in polymerase chain reaction amplification products of breast cancer patients. Anal Bioanal Chem. 2013;405(10):3097-3103. 